\title{
Parapsychological Reflections on Some Tunnel Experiences
}

\author{
C.T.K. Chari \\ Department of Philosophy and Psychology \\ Madras Christian College \\ Tamilnadu, India
}

\begin{abstract}
This paper examines tunnel experiences, which have been discussed by Raymond Moody, Kenneth Ring, and Kevin Drab in the context of near-death experiences. It is argued that tunnel experiences, even when possibly triggered by psi cognition, are not always associated with near-death experiences or out-of-body experiences. A proposed definition of pseudo-hallucinations is adapted to possible psi-induced tunnel experiences. Six categories of tunnel and related experiences are tentatively distinguished: (1) hallucinated circular or oval shapes or spirals; (2) tunnels used for an ostensible "distant vision" but not for subjective traveling; (3) tunnels used both for an ostensible "distant vision" and for subjective traveling; (4) tunnels associated with ostensibly mediumistic and mystical OBEs; (5) tunnels of NDEs; and (6) tunnels used in ostensible precognition and postcognition. The classification does not deny possible neural correlates and is open to revision. A transactional view of visual perception is accepted, and the hypothesis is advanced that the tunnel is a subconsciously devised artifact for overcoming a spatial and/ or temporal gap at the perceptual level created by psi cognition intruding into consciousness. The view is compared with the approaches to tunnel experiences sketched by Robert Crookall, Itzhak Bentov, and Kenneth Ring. A new solution of why tunnels are missing in many OBEs and cases of "clairvoyant travel" is offered.
\end{abstract}

\section{The Tunnel as a Possible Psi-Induced Pseudo-Hallucination}

This paper suggests that the tunnel experience, which is regarded as a significant aspect of some near-death experiences (NDEs), may be too complex and variable to have a single explanation. That the tunnel may not always be associated with the NDE seems to be admitted. My argument is that the tunnel, even when it occurs as a paranormal experience, is not always and unambiguously associated with an out-of-body experience (OBE). Trivial as this non-correlation may appear, it nevertheless raises some questions about the interpretation of "awareness" in the quasi-spatial imagery of the border states between "waking" and "trance." A corollary of my argument is that the term "hallucination" may carry different meanings in the conte xts of possible psi-induced misperceptions and other misperceptions that are not so induced. 
Esquirol's definitions (1837) of illusion as a "false perception of external objects" and of hallucination as a "subjective memory image" were radically altered by the later extrapolation by investigators of a class of "active illusions," meaningful projected memory images that tend to become "integrated hallucinations," perhaps not very different from the "idiosyncratic synthesis of image and percept" postulated by Frederic W.H. Myers in the classical studies of phantasms (1886) he conducted with Edmund Gurney and Frank Podmore.

Formulating differential criteria for the whole range of hallucinations is a formidable task today. Two comprehensive symposia, one edited by L.J. West (1962) and the other by Ronald Siegel and West (1975) only served to demonstrate the phenomenological similarities of various hallucinations irrespective of their etiology (whether induced by drugs, sensory deprivation, hypnosis, meditative practices, psychotic conflicts, hysterical distubances, etc.). Even the older distinction between sensory (peripheral) and ideational (central) hallucinations has tended to fade away with advances in neurophysiology. C.W. Savage (in Siegel and West, 1975) would persuade us that perceptions, dreams, fantasies, hallucinations, and thoughts are not sharply distinguishable experiences on a continuum. Any term in the series can generate any other in appropriate contexts. The blurring of lines has been exploited by critics of NDE and OBE research.

For the purposes of my paper, I shall rephrase an old distinction of Kandinsky's between hallucinations proper and pseudo-hallucinations. In a pseudo-hallucination, as I regard it, the normal, conscious, waking mind is aware that objective perception is lacking and yet is also aware that the anomalous pseudo-perception is not a wish fulfillment, fantasy, or dream. A pseudo-hallucination, then, occurs when a subject recognizes that he is the victim of an anomalous perceptual experience but is unable to provide any plausible explanation of the anomaly even after prolonged self-inquiry and self-criticism.

Karlis Osis and Erlendur Haraldsson (1977, pp. 54-55) define a "hallucination" as an "image coupled with a misapplied sense of realness" and distinguish it from an "ESP-based hallucination," which has an appropriate "sense of realness." But a "sense of realness" suggestive of a psi context has to be confirmed by a later scientific inquiry, possibly of an indirect and circumstantial kind, as Osis and Haraldsson believe. There is no reliable and valid index separating psi hallucinations from all other hallucinations before the confirmation of an extra-sensory link. I suggest that psi hallucinations, at least of the waking moments of a near-normal mind, fall within my subclass of pseudo-hallucinations and, in that sense, are different from 
psychotic, hysterical, drug-induced, or prolonged-sensory-deprivation hallucinations.

It is quite misleading to assert that pseudo-hallucinations are experiences of psychologically naive subjects alone. Two decades ago, I referred (Chari, 1962) to R.R. Willoughby's impressive demonstration of "ghosts" presented as visual phantasms to some highly sophisticated professionals engaged in psychological research. E.J. Dingwall (no date but circa 1950), a highly qualified and skeptical parapsychologist, reported two personal experiences of hypnagogic images occurring in the border state between waking and sleeping, one of a curious Chinese face and the other of a blue star that disappeared with a loud crackling noise like the one emitted by an electric spark. Dingwall, who was extremely well read in the literature on hallucinations, had no explanation to offer. His hypnagogic images shared the important characteristic of "as if but not really out there" with the class of pseudo-hallucinations. Dingwall was no neurotic or psychotic but a highly intellectual medical and scientific researcher. His hallucinations, in spite of their "sense of realness," were not psi induced.

In psychotic hallucinations (for an interesting personal account, see Lang, 1938, 1939), there is generally no subjective management of the situation; insight into the experience is lacking, and there is active belief in the content of the hallucination and even resistance to a scientific probing. In a recent apparent exception reported by Morton Schatzman (1980), his schizophrenic patient Ruth seemed capable of initiating at will complex hallucinations like phantoms of people she knew. After reading the report, I am persuaded that since the trances were followed by partial amnesia, true insight into the subjectivity of the phantoms was lacking even when a kind of subjective control existed. My criteria for pseudo-hallucinations are not met.

F. Barron, M.E. Jarvik, and S. Bunnell (1964) contend that the psychotomimetic (hallucinogenic) drugs rarely produce a psychotic hallucination in the classical sense. The subject, they say, can distinguish reality from the psychedelic vision even when the influence of the drug is compelling. But they at least imply that the behavioral accompaniments of the psychedelic state (poor arithmetical reasoning, spelling, drawing, lack of motivation, and lack of cooperation) and the measurable (pupillary, vascular, EEG) correlates are not distinctive of the near-normal state or even of a non-specific arousal of no great intensity.

I believe some tunnel experiences are psi-induced pseudo-hallucina- 
tions not associated with either NDEs or OBEs. On my reading of the situation, Kevin Drab's (1981) query, "Are tunnel experiences real or hallucinatory?" is belied by the "as if" character of pseudohallucinations. A schema that requires absolute choices between "fact" and "fiction" provides little scope for any inquiry into extrasensory capacities. I believe that alternative schema for possible psi cognition at work in pseudo-hallucinatory tunnels have not so far been proposed. Bruce Greyson (1981), in his spirited rejoinder to Michael Grosso, does refer to the psi-mediated-instrumental-response (PMIR) model of Rex Stanford. The model, which has been criticized by Stephen Braude $(1980,1981)$ on what seem to me cogent philosophical grounds, is too limited to be of use in evaluating complex psychical experiences. In an earlier paper (Chari, 1966), I pointed out that the implicit metalanguage of fashionable theories of communication presupposes a neutral observer who has full access to both ends of the informational process. Psi-induced pseudo-hallucinations, in which the only significant evaluation of the experience may have to be conducted by the percipient himself, present great difficulties for both the structural and statistical-semantic versions of current information theory. Any analysis, if it is not to be an empty and a priori piece of theorizing, must keep close to the subjective reports, however distasteful that may be to fastidious investigators who would rather rely on objective methods.

\section{A Tentative Typology of Tunnel and Related Experiences}

Raymond Moody (1975) remarks that the tunnel in NDEs is also described as a cylinder, funnel, sewer, cave, valley, void, or simply a dark space. Perhaps the high variability of description may be symptomatic of the NDE. I shall pay special attention to dimensional criteria by arranging, in crude and schematic outline, tunnels and related experiences in a graded series though not necessarily in the order of ascending complexity, since all tunnel experiences may be incredibly complex.

1. Visual apparitions enclosed in circular/oval spaces. We have, to start with, some curious cases of visual apparitions enclosed in circular and oval spaces. In a case discussed by G.N.M. Tyrrell (1953), the subject, Gottschalk, had written a letter to a Thorpe about a recitation to be given at Prince's Theatre. Thorpe was then acting in two plays at the theatre. Gottschalk was walking along the road to meet some friends when there suddenly appeared before him a disc of light. In the illuminated space were two manicured and whitened hands, un- 
mistakably those of Thorpe, handling the letter Gottschalk had written earlier. At about this time, Thorpe actually was opening and reading the letter. The evidence for psi cognition in this case is weak except for the asserted coincidence of the objective event and the subjective experience in time. How close the coincidence could have been is not clear from the narrative.

I have three comments on this category of psi-induced circular and oval pseudo-hallucinations. First, the circular hallucinatory spaces do not have much depth; they are not cylinders, tubes, or funnels. They seem to be between some self-contained "crystal-visions" and the "tunnel of concentric circles" described by a subject of Moody (1975). A spiral, whether Archimedean, logarithmic, or hyperbolic, has less depth than a stereoscopic figure. A computer program can develop intermediate figures of varying depth. The subject of $R$ alph Shirley (no date but circa 1930), who seemed to be looking through the wrong end of a telescope, might have been closer to the tunnel than to the pseudo-visual circles or spirals.

Second, the bright disc of Gottschalk seemed to be on a different plane altogether from the ordinary objects on the road.The illuminated circle, in fact, was not very different from the "medallion portrait" in which a collectively perceived apparition of the head of a deceased Captain Towns showed itself in another case recounted by Tyrrell (1953). Tyrrell remarks that the "medallion portrait" occupied a "space of its own" unconnected with the wardrobe on which it was seen. The "mirror visions" described by Ibn Khaldoun (Barrett, 1911) nearly seven centuries ago hovered apparently on a misty curtain between the observer and the mirror. The description matches the more recent descriptions of the "clouding" of the crystal or the globe as seen by the sensitive or the "scryer." Ostensibly psi-induced "crystal-visions," although they may appear to follow optical laws of magnification, reflection, refraction, and color contrasts, for sophisticated subjects who have learned to expect the effects, are yet basically unrelated to ordinary perceptual space (Myers, 1903). There is an analogy, I think, between these circular and oval hallucinatory shapes and the after-images described by Heinrich Klüver (1926), which, in mescal-induced states, transform themselves into colored shapes, for instance violet circles, most imperfectly localized in perceptual space. Poorly defined and indescribable pseudo-sensations seem to involve the mid-temporal lobe, often the anterior and mesial surfaces (Neppe, 1981). Is it possible that psi cognition may activate the relevant cortical areas to produce an indistinctly localized pseudo-hallucinatory illuminated circle? The etiologies would then be different for two 
similar classes of experiences, the mescal and the psi-induced images.

Third, there is no large involvement of the percipient in the hallucinatory space. He does not experience his own location or movement in the shallow discs or circles. D. Scott Rogo's friend, Blue Harary, in his OBEs sometimes felt himself identified with a moving ball of light (Rogo, 1976). A moving ball of light with which the subject identifies himself and a shallow circle he simply sees before him are very different. For the most part, in my category 1 of pseudo-hallucinations with a possible psi context, there is no weird transposition of subject and object of the kind that may occur in mescal intoxication (Klüver, 1926) and in other psychotomimetic states (Barron et al, 1964) when the object becomes endowed with mental qualities whereas the subject becomes a passive object with no "interior mentality." Whether the transposition in some degree occurred for Blue Harary is not clear from Rogo's description.

2. Psi-induced pseudo-hallucinatory tunnels. Mrs. Dawson Scott by her own admission was an agnostic about psychic realities. Nevertheless, in 1926 she published some automatic scripts purporting to come through her hand, containing some verifiable information, from four "spirit communicators." One of them claimed to be her late husband. A little before Dawson Scott developed automatic writing, she had a series of unanticipated and startling tunnel experiences (Dawson Scott, 1926), though regrettably she does not date them as she dates her automatic scripts. Relaxing in her room upstairs and closing her eyes, she could see right in front of her a dark tunnel. Extending her gaze into it, but apparently not traveling along it subjectively in any full-scale fashion, she could see what looked like distant scenes, colored seas, houses, and even trains passing by.

When a Mrs. Craven, who also had lost her husband, came to stay as a guest in Dawson Scott's home, the latter had a further series of even more startling tunnel experiences (Dawson Scott, 1926). Emptying her mind of all thoughts (Dawson Scott's own characterization of her mental state), closing her eyes, and mentally gazing out of the far end of the tunnel, she could see what looked like a ghostly counterpart of her drawing room downstairs, since the walls had dissolved in a colorless light. Mrs. Craven appeared to sit in utter dejection on a chesterfield in the room. On a sort of aerial couch connected by a twisted rope to the person of Mrs. Craven lay Mr. Craven (such was the impression) in profound slumber. In subsequent inspections, though not excursions via the tunnel, of the strangely altered drawing room, Dawson Scott became aware that "Mr. Craven" was gradually awakening. Presently "he" was fully awake, and she received a 
peremptory auditory message from him asking her to inform his wife of his survival of bodily death. Dawson Scott, still entrenched in her conscious unbelief and fearing also the ridicule of Mrs. Craven, who shared the unbelief, ignored the message even when 'Mr. Craven's voice" persisted for days during her rounds of duties.

My second example, that of a three-dimensional halo or cylinder, is drawn from the records set down scrupulously, with statements by independent witnesses, at the turn of the century by the gifted sensitive, Vincent Turvey (1911). He became a semi-invalid after a pulmonary accident (described by his close friend, W.T. Stead, as a "pyopneumothorax"). Turvey then had a wide variety of evidential paranormal experiences and some startlingly vivid OBEs, which, although he was somewhat disposed to spiritualist beliefs, he described with measured doses of skepticism, holding that he was not conscious$l y$ responsible for all his queer "visions." W.T. Stead, in his preface to Turvey's book, quotes his friend as saying that in his ordinary "distance clairvoyance" a dark tunnel would apparently cut through all intervening physical objects, enabling him to see distant scenes. Turvey, who was a practiced "traveler out of the body," did not regard the tunnel experiences as OBEs. A remarkable aptitude Turvey developed between 1905 and 1908 was what he quaintly called "phone-voyance." If an utter stranger, a mile or two away, telephoned Turvey, the latter, standing at his end of the telephone line, could see through a subjective three-dimensional colored (heliotrope or violet) halo. I suggest that this was only a variant of the dark tunnel associated with Turvey's "long-distance clairvoyance," exercised in moments when he was probably more relaxed (with closed eyes?) than when he was telephoning people. Looking through the illuminated tube into a central window, as it were, with a colorless light as its background, Turvey could see and describe in detail the person or persons in rooms at the other end of the line. Occasionally he saw figures at the other end that, from the descriptions he gave, were recognized to be deceased persons. A curious experience Turvey had during what he called his "genuine phone-voyance" was that his "mentality" appeared to "ooze out" along the telephone line for a yard or two. A mirror image of the two copper wires in the mechanical set-up at his end of the telephone (i.e. an image of the wires in reversed positions) would arise on these occasions.

In both sets of experiences I have summarized, those of Dawson Scott and Turvey, more or less satisfying my criteria for pseudohallucinations, the tunnel was three-dimensional and not a shallow disc. Second, there was active personal involvement in the hallucinated 
spaces, not in the sense of locomotion but in the sense of looking through the tunnel and beyond. With a little adjustment and orientation (I suppose the "oozing out of the mentality" in Turvey's case and the straining "to see beyond the tunnel" in the case of Dawson Scott), the subjects apparently could look into distant rooms without entirely shifting their own position in subjective space. In other words, for both subjects there was not the complete or near total loss of coenesthetic bodily anchorage reported in a large number of OBEs. More explicitly, Dawson Scott and Turvey seemed aware of the distant end of the tunnel and the rooms beyond even while they felt they were anchored at the near end of the tunnel. In neither case was there a "seeing oneself" or autoscopy, which is a striking feature of many OBEs and which Celia Green (1968) distinguishes carefully from "seeing one's double" or autophany. In the latter case, the subject retains his usual spatial point of view, seeing his own double as an "apparition." Turvey did not regard his tunnel experience as an OBE. Neither did Dawson Scott. The auditory hallucination of "Mr. Craven's voice," with its note of urgency, which was originally correlated with the visual phantom of the altered drawing room, persisted unchanged, as did Dawson Scott's ordinary bodily surroundings. This indicates her somatosensory and other thresholds were relatively unaltered in the tunnel experiences. The tunnel experiences of Dawson Scott and Turvey were not ecsomatic, to use Green's term.

A third feature of both sets of experiences, those of Dawson Scott and Turvey, was the apparent presence of the dead in the tunnel settings. Critical introspections and doubts in both subjects could not erase the overwhelming impression of "as if out there even though not really" that is characteristic of pseudo-hallucinations in my description. I note in this context that Kenneth Ring (1980) refers to a woman mentioned by Moody who, during a tunnel experience, saw the phantom figure of a friend apparently returning through the dark passage. It transpired later that the friend had suffered a severe cardiac arrest and nearly died. She had revived at about the time of the tunnel experience. The apparent presence of the dead in tunnel settings needs to be investigated further. It is not clear to me whether Moody's informant was only looking through her tunnel or subjectively traveling along it by shifting her apparent spatial position. An intriguing feature of the case is the apparent location (and locomotion?) of the phantom inside the tunnel. The visual phantoms of deceased persons hallucinated by Dawson Scott and Turvey were outside the tunnels, in strangely altered rooms beyond. Is all this elaborate symbolism of the dead significant or just accidental? I pose the problem for further research. 
3. Psi-induced tunnel experiences. The case of Hermione Okeden (pseudonym) of South Africa reported by Ralph Shirley (no date but circa 1930) is representative of a third group of apparently psi-induced tunnel experiences. Okeden would relax and close her eyes (very much as Dawson Scott did) and could not only gaze along a long, dim tunnel but also travel subjectively along it by shifting her apparent spatial position. She would emerge from the distant end of the tunnel and apparently be with friends in their rooms or even among strange people in strange surroundings. Taking the case for what it is worth (there is no independent corroboration of the extra-sensory nature of the "distant visions"), there was apparently a much greater loosening of Okeden's bodily anchorage than that of Dawson Scott in her tunnel experience or Turvey in both his "long distance clairvoyance" and his "phone-voyance." More explicitly, Okeden, in her pseudohallucinatory experiences, seemed to be mostly at the far end of the tunnel and little or not at all at the near end. There may be a whole series of delicate shifts or transitions by which my category 2 shades into category 3. Experiences, contrary to some theories of OBEs, may be a matter of degree. Theories of the "silver cord" and the "astral body" (parasomatic experiences) must be subjected to the most searching epistemological scrutiny.

I quite realize that reports of complex hallucinations, even when they occur in a near-waking state, may be prone to retrospective falsification by subjects or even confabulation in the telling. Greyson (1981) rightly admonishes us that the NDE subject who describes psi cognition as having taken place during a period of complete coma may be altering the sequence of events after recovery. The possibility seems to me large, especially since psi cognition arises from a deep stratum of the mind. There is great danger of self-deception both in the subject and in the experimenter with his preconceptions. Neither can be too critical or too skeptical in reports.

Okeden does not tell us whether she ever saw figures of the dead inside or outside her tunnel. Possibly she did not. In any case, I am unsure how far the puzzling feature divides various tunnel hallucinations. The peculiarities of symbolism may be those of the individual and not of the subgroup regarded as a whole. Our surveys have to be wide and detailed.

4. Psi-induced tunnels involving OBEs. Still another class of apparently psi-induced tunnel experiences includes reports of complex mediumistic and mystical OBEs. Whether this category satisfies all my criteria for pseudo-hallucinations, especially the retention of waking consciousness with its critical powers of introspection and 
analysis, is questionable. The mediums and mystics of this category seem to be lifted very much above their terrestrial habitations. Annie Brittain, a well-known English professional medium who corresponded with me (Brittain, 1966), seemed able to travel subjectively far beyond her body (Brittain, 1935). She would move from one postmortem condition (in spiritualistic jargon, "sphere") to another. She hallucinated figures of the dead, some known and many unknown, in these transitions. The deceased figures appeared to be surrounded by a shaft or tunnel of golden light cutting through the gloomy mists as it were of the "lower spheres." The descriptions are typical of a very large body of spiritualistic literature.

J.H.M. Whiteman, a philosopher and mathematician, in reporting (1961) his own mystical experiences in rich detail, testifies that on one occasion he seemed to go through a dark tunnel into what looked like bright sunshine. On another occasion he saw a "white cloud" in an "opening." He speaks of "interpenetrating spaces." His consciousness seemed to dwell simultaneously in several different spaces permitting "comings and goings" of "personality" through "doors" and "passages" of strange "buildings" (p. 215). Spatial imagery is present in all spiritualist descriptions of the "beyond."

In cases belonging to this fourth category of my classification, the tunnel when it occurs apparently transports the subject to "another world" altogether, with highly symbolic correspondences between states of consciousness and the hallucinated spaces. Whiteman (1961) regards his tunnel as a "fantasy construction." C.G. Jung (1957) notes that mystical access to the "Great Light" is through a descent into a dark cave. Dawson Scott, Turvey, and Okeden, by contrast, in their tunnel experiences were never quite out of "this world" even when objects in it had an altered appearance. Are there intermediate states with tunnels opening into a hinterland of both worlds? Again, more research is needed.

5. Tunnels and paranormal cognition in near-death experiences. The next group of tunnel experiences is the class of NDEs with an apparently paranormal psi cognition at work conveying detailed information about near and distant events that the nearly dead or dying person could not by any means have acquired normally. This category of tunnel is one facet of Ring's painstaking and scholarly study (1981). In view of the profound alteration of consciousness in the NDE, notably the ineffability and the feeling of surpassing peace, the question arises whether the tunnels of NDEs fit my formula for pseudo-hallucinations. Moody's pronouncements (1975) give room for pause. On one hand, he argues that many NDE subjects can dis- 
tinguish between waking experience and a dream or hallucination, and that the anesthetic hallucination of death, where it is induced by the the administration of a drug, is atypical of the whole class of NDEs. On the other hand, he suggests that psychedelic and near-death visions may both point to realms beyond ordinary experience. Other medical researchers like J. Ehrenwald hold that a life-threatening situation can trigger an apparent $\mathrm{OBE}$ associated with an NDE even when the subject has no well-articulated belief in immortality (Ehrenwald, 1974). I have remarked that the tunnels of Moody's informants are described in various ways and not always as tunnels. The tunnels of Dawson Scott, Turvey, and Okeden were relatively stereotyped and constant, judging by the descriptions. I am inclined to suppose that the tunnels of my category 5 are like those of category 4 opening into "another world." The question remains whether some NDErs look into the far end of their "dark passages" while being anchored to the near end. Are some NDEs ecsomatic without being parasomatic, to use Green's terminology? In parasomatic tunnel NDEs there should be some means by which the altered consciousness moves across the tunnel.

6. Tunnels involving movement backward and forward in time. I must deal briefly with my last category of tunnels associated with psi-induced hallucinations. Stead quotes Turvey (Turvey, 1911) as saying that his tunnels could cut through not only space but also time. The precognitive or postcognitive tunnel experience seems somewhat rare judging by my own studies (Chari, 1951). The classical tau and kappa effects of experimental psychology (Cohen, Hansel, and Sylvester, 1953) show that the spatial and temporal components of perceived events are interdependent. Possibly this applies also to the space and time separations of hallucinatory experiences. The precognitive or postcognitive tunnel raises questions about time as well as consciousness. Turvey's tunnel cutting through time was not claimed to be an OBE. The supposed or asserted space-time transcendence of OBEs provides no adequate explanation for this category of tunnel.

The six categories of tunnels I have distinguished are by no means mutually exclusive. There may be all kinds of subtle overlappings. My typology is open to revision and criticism in the light of further studies. Classifying tunnel experiences into recurrent and nonrecurrent may not be valid. A presumably nonrecurrent tunnel associated with an NDE may, after the patient's recovery, generate recurrent tunnel experiences, especially if psi cognition is released by the NDE. The possibility is suggested by Michael Sabom's data, if I may judge by Grosso's review (1981). 
Some Incomplete Theories of Tunnel Experiences

I regard some proposed theories of tunnel experiences as incomplete if only because they ignore possible psi cognition at work in at least some of the experiences.

1. A simple hypothesis of the tunnel is provided by the supposed entoptic transfiguration of retro-retinal and chorio-capillary structures into bizarre images in hypnagogic and other states. It is evident that the etiology will not hold for all tunnel experiences.

2. I cannot agree that the psychoanalytic doctrine of birth-death symmetry (Anthony, 1940), that is, the unconscious assimilation of birth and death into similar images, coming out of or going into a dark tunnel, is the universal key to the experiences. The psychoanalytic doctrine, however, may be relevant to NDEs, with or without the tunnel experience, occurring in cultures in which reincarnation is held as an article of religious belief. Jung (1957) discusses the complexities of "rebirth" symbolism. Osis and Haraldsson (1977) do not examine the possible interlocking of reincarnation belief and the NDE in India. Judging by my own Indian data, the question has to be debated in greater detail.

3. The tunnels of my categories do bear some resemblance to one of the hallucinatory constants postulated by Klüver (1942) in his classical studies, but they cannot be wholly reduced to the latter. In apparently psychical pseudo-hallucinatory experiences of tunnels, especially those of my categories 2 and 3, there are not too many abnormal alterations in the number (polyopia), sizes (dysmegalopsia), and shapes (metaphorphopsia) of objects in the hallucinatory space. Klüver argues that these pervasive changes in objects are symptomatic of the operation of his form constants.

4. Siegel (1980) draws attention to the phenomenological similarities of all tunnel experiences. He conjectures that the subjective bright lights may be caused by the electrical activity of the brain involving a lowered threshold for phosphenes and also more generally caused by the mimicking of retinal effects by the central nervous system. Possibly we have to consider the activity of the temporal lobe. Simple visual hallucinations of flashes, spots, and dots may arise from the activation of the occipital area. Complex psychosensory hallucinations involving several sensory modalities, with some depersonalization and de-realization (Neppe, 1981), may point to involvement of the temporal lobe. Brodmann's areas 42 and 22 may be called into play in auditory hallucinations that are not simple sounds like buzzing or hissing. Dawson Scott's tunnel led to auditory as well as visual halluci- 
nations involving phantoms. Although the symptoms of temporal lobe disorders are variable, a certain constancy for individuals may prevail (Neppe, 1981). While I admit these possibilities, I repeat that it is not the simple choice ESP or temporal lobe activation that is before us. The former, for all we know, may underlie the latter in some cases.

Sophisticated methods of studying the brain, for instance by computerized axial tomography or by the more recent positron emission tomography, are easy to suggest, but they are difficult to apply to individuals while they are having hallucinations. We cannot dispense with subjective reports even if they are inevitably exposed to numerous possible errors of memory, hypomnesia, cryptomnesia, and varying forms of paramnesia.

Drab (1981) adopts Siegel's general approach to tunnel experiences, but he is unable to decide between the play of neural patterns and a meaningful organization imposed on them. I cannot agree with him that the tunnel is a dispensable auxiliary aid to the subjective experience of travel. His examples may support the contention; mine do not. The symbolism of the near and distant ends of the tunnel seems to be tied in an essential way with the distribution of awareness in relation to its coenesthetic bodily anchorage in my categories 2 and 3. The apparent presence or movement of the dead inside or outside the tunnel complicates the problem further, as I have remarked earlier.

\section{A Suggested Framework for Psi-Induced Tunnel Experiences}

Recognizing that tunnel experiences are highly variable and may have several possible explanations, we may still seek a common theoretical framework for the subclasses of possibly psi-induced pseudo-hallucinatory tunnel experiences. We may regard perceptual activity as furnishing a kind of framework within which the individual constructs a personally meaningful environment.

If the ordinary perceived world is regarded as an inter-personal network offering us the best possible chances of effective action in our daily life, then unusual, and possibly psi-induced, tunnel pseudohallucinations signal the failure of the customary social and postural integration of visual space. J.C. Licklider (1960) remarks how through life-long experience a nearly one-to-one correspondence has developed between vision and manual responses. The arms and the hands, he explains, move in relation to the head and eyes. The correspondence has to be made nearly linear, since linear correspondence is the only 
transformation that is invariant under translation and magnification. With increasing collapse of visual, postural, and muscular integration in visual hallucinations, internal, personal, and, possibly, little understood socio-cultural themes may tend to prevail more and more. The departure from linear isomorphism because of the projection of the retina upon area 17 of the cortex is negligible and troubles ordinary visual perception very little. It at least suggests that in illusions a certain non-linearity becomes marked.

I think the psi-induced pseudo-hallucinatory tunnel is an attempt to surmount a potential discontinuity between the pseudo-hallucinatory visual world and the ordinary perceptual world. I hold that the discontinuity is basically an interruption of consciousness by the sudden intrusion of psi cognition at a deep, possibly even neural, level. There could, of course, be other analogous.interruptions arising from other causes. I submit that gaps in the general stream of consciousness are more often than not overcome to produce a deceptive continuity. As Henry Head observes in his classical study of aphasias (1926), "In all discussions of the relation of mind to body, stress is laid on the continuity of consciousness. But this continuity is produced by habitually ignoring gaps (pp. 490-491) ... The mind acting as a whole not only ignores gaps in general consciousness, but habitually ignores many possible experiences on some specific level as that of sensation" (p. 541). Even without drawing upon technical considerations relating to the body-image (Smythies, 1953), I judge that the available evidence points to a comprehensive integration, or interaction, of all the sensory (exteroceptive, proprioceptive, and interoceptive) modalities. To take a specific example, the sensitivity of the dark-adapted eye (which is surely relevant to the "relaxed" states of subjects like Turvey, Dawson Scott, and Okeden) may be affected by changes in the other exteroceptors and those in muscle, tendon, and bladder.

According to my suggestion, the visual hallucinaton of the tunnel overcomes a spatial and/or temporal gap created by a disruption of general consciousness. The tunnel is a subconsciously devised artifact (possibly allied to certain non-linearities of visual illusions) that introduces apparent continuity into the perceptual field by a hallucinatory extension, and also some curtailment, of the counterfeit visual world. The disruption of consciousness, then, is more than a "blackout." It is an alteration as well of the texture and range of consciousness conveying ostensibly paranormal information. My view may be compared with the approaches to tunnel experiences sketched by Robert Crookall (1980). For Crookall, the spatial continuity of the tunnel compensates for a temporal break in consciousness or black- 
out. Bentov and Ring admit this element but argue that there is a suggestion in the tunnel of a shift in the level of consciousness. For me also, it is the disruption in consciousness that necessitates the artifact of the tunnel supplying an apparent spatial and/or temporal continuity. Not all psi-induced tunnels, however, as I view them, are merely symbols of continuity for consciousness shifting its level. There is in some tunnel experiences something of the mimicking of retinal effects by the central nervous system to which Siegel has drawn attention. The tunnels of my categories 2, 3, and 6 supply an essential element of continuity at a perceptual and not simply at an ideational level. I suspect (I may be mistaken) that the shifts in the level of consciousness postulated by Bentov and Ring are more ideational than perceptual. In my hypothesis, the interdependence of perceived spatial and temporal intervals, suggested by the classical tau and kappa effects, is carried over into the pseudo-visual world of hallucinations.

The demand for some continuity of hallucinatory with somatosensory and other perceptual experiences, in subjects who are not psychotic, can be illustrated elsewhere too in the extensive literature on hallucinations. Klüver (1928) and Barron et al (1964) note that ordinary visual and mescal experiences may not be cut off from each other for the subject experiencing both of them. Adapting Klüver's terminology (1926) to my purposes, a change in the apparent object (Gegenstand) accompanies and emphasizes the change in the Iconsciousness (Ichbewusstsen), its texture and range. If I am right in my approach, the tunnel, when it accompanies an NDE, may be analogous in structure and function to the tunnels of my category 4 , involving profound changes in consciousness, for instance, intense personal significance (presque vu), and feelings of harmony (kalopsia) overcoming the disharmony (kakopsia) of ordinary life. Possibly we have here a shift in the level of consciousness, as urged by Bentov and Ring. Their symbolic tunnel is similar to my categories 4 and 5 .

A crude analogy drawn from neuropsychiatry may illustrate my preoccupation with perceptual spatio-temporal continuity. A parietal lobe syndrome (Critchley, 1951) may be revealed in an anomalous distant vision (teleopsia) as well as a disturbed temporal ordering of experience (Zeitordnung). The abnormal continuities compensate for a deep cortical disruption. Dream states by comparison are more symbolic. Some dream drawings seem to achieve a curious synthesis of the familiar and the unfamiliar. In some dream drawings reproduced by F.S. Perls (1947), the tunnel does occur, but as an apparent pictorial projection of repressed aggressive impulses into a semi-closed space. Tunnels, therefore, can be meaningful links in perceptual as 
well as in more symbolic continuities.

My hypothesis serves to explain the interesting differences between the dark tunnel of Dawson Scott and the illuminated tunnel of Turvey. Dawson Scott during her tunnel experience was resting with closed eyes. Her somatosensory, kinesthetic, and tactile thresholds were probably relatively unaltered. A dark tunnel supplied the element of continuity between the pseudo-visual hallucination and her other perceptual experiences. For Turvey, sitting or standing in a well-lit room telephoning people, a dark tunnel would have disrupted perceptual continuities. An illuminated tube or tunnel, with an open window as it were at the other end, fit very well with the total perceptual situation. The dark tunnels of his clairvoyance in time as well as in space probably were appropriate to more relaxed subjective states. For both Dawson Scott and Turvey, the hallucinatory extension of the perceived world preserved intact the distinction between the "up" and "down" directions of both the normal vertical visual axis and kinesthetic-vestibular responses to gravity. Complex somatosensory experiences seem to derive from the parietal lobes (Critchley, 1951; Neppe, 1981). The "aerial couch" hallucinated by Dawson Scott was not suspended upside down or askew even if it appeared to be floating like a balloon. The phantoms Turvey hallucinated at the other end of his illuminated tunnel were more or less in correct perspectives. There was only a slight visual inversion of right and left in the hallucinated mechanical arrangement at the near end. I submit that these hallucinatory spaces are very different from the "Lilliputian spaces" of chloral delirium or the "Brobdingnagian dilations" of hashish visions. The tunnels of my categories 4 and 5 may involve sweeping changes in the background distribution (Hintergrudfunktion).

\section{Why Are Tunnels Absent in Many OBEs and Psi-Induced Hallucinations?}

Horace Leaf, a researcher of mediums, lays down the general principle that in distance clairvoyance, "the object is seen as if through a tube or tunnel" (1918, p. 165). I have found no evidence for so sweeping a principle. Many accounts of OBEs and "traveling clairvoyance" (Green, 1968; Prevost-Battersby, no date but circa 1930), the "astral travels" of Sylvan Muldoon, Oliver Fox, and Gerhardi (Shirley, no date but circa 1930), and the mediumistic excursion into the "beyond" of Mrs. Osborne Leonard (1931) make no mention whatever of a tunnel. Why is the tunnel missing in all these cases? Bentov (1977), Ring (1980), and Drab (1981) regard the tunnel as a dispensable auxiliary aid to a shift in consciousness or a 
subjective experience of travel. Emphasizing as I do the tunnel as an element in perceptual continuity, I have to cast about for a different solution.

I suggest many psi-induced hallucinations may be synesthesias of a new kind: paranormal fusions of pseudo-sensations or images with one type of imagery furnishing important links. Charles E. Osgood (1953) pronounces, on the basis of a large body of empirical research, that synesthesias deal with meaning as grasped by the individual. Various modalities are made parallel by the subject, and translations are made from one modality to the other on the basis of key language metaphors. I suspect that something like this is true for many OBEs. Selected modalities (vision for some subjects but not for all) serve as keys in the translation. I seem to find an indication of this in the studies of Leonard's mediumship pursued by Lady (Una) Troubridge $(1922,1924)$. Troubridge found that whereas Leonard in her ordinary life had average auditory acuity, in the trance state she had a marked hyperaesthesia of hearing to which Leonard, too, testified. The auditory hyperaesthesia persisted even in the deeper trance when the "spirit controls" and "spirit communicators" emerged. Is it too much to claim that auditory spaces (serving possibly as a background for "spirit conversations") were more important for Leonard than visual spaces even when she hallucinated the latter? Perhaps this applies to other "astral travelers" who do not use the tunnel to establish the key continuities of hallucinatory spaces. Shirley (no date but circa 1930) makes the casual remark that Sylvan Muldoon, during an OBE, heard the clock strike two first and then saw the hands registering the hour. Turvey by comparison seems to have used visual spaces as keys in the continuities of OBEs.

\section{REFERENCES}

Anthony, S. The Child's Discovery of Death. London: Kegan Paul, Trench and Trubner, 1940.

Barrett, W.F. Psychical Research. London: Thornton Butterworth, 1911.

Barron, F., Jarvik, M.E., and Bunnell, S. The hallucinogenic drugs. Scientific American, 1964, 210(4), 29-37.

Bentov, I. Stalking the Wild Pendulum. New York: E.P. Dutton, 1977.

Braude, S. Letter. Journal of the American Society for Psychical Research, 1980, 74, 258-263.

Braude, S. The observational theories: a critique. Journal of the 
American Society for Psychical Research, 1979, 73, 349-360.

Brittain, A. Twixt Earth and Heaven. London: Rider, n.d. but ca. 1935.

Brittain, A. Personal communication, 1966.

Chari, C.T.K. "Buried memories" in survivalist research. International Journal of Parapsychology, 1962, 4(3), 40-61.

Chari, C.T.K. A note on precognition. Journal of the Society for Psychical Research, 1951, 36, 509-518.

Chari, C.T.K. On information-theoretic approaches to ESP. International Journal of Parapsychology, 1966, 8, 533-553.

Cohen, J., Hansel, C.E.M., and Sylvester, J.D. A new phenomenon in time judgment. Nature, 1953, 172, 901.

Critchley, M. The Parietal Lobes. London: Edwin Arnold, 1951.

Crookall, R. More Astral Projections. London: Aquarian Press, 1964.

Crookall, R. The Study and Practice of Astral Projection. London: Aquarian Press, 1961.

Dawson Scott, C.A. From Four Who Are Dead. London: Arrow Smith, 1926.

Dingwall, E.J. Very Peculiar People. London: Rider, n.d. but ca. 1950.

Drab, K. The tunnel experience: reality or hallucination? Anabiosis, $1,126-152$.

Ehrenwald, J. Out-of-the-body experiences and the denial of death. Journal of Nervous and Mental Disease, 1974, 159, 227-233.

Esquirol, J.E.D. Des Maladies Mentales. Paris: J.-B. Bailliere, 1837.

Green, C.E. Lucid Dreams. Oxford: Institute of Psychophysical Research, 1968.

Greyson, B. Towards a psychological explanation of near-death experiences: a response to Dr. Grosso's paper. Anabiosis, 1, 88-103.

Grosso, M. Book review: Recollections of Death: A Medical Perspective, by Michael Sabom, M.D. Anabiosis, 1981, 1, 171-176.

Gurney, E., Myers, F.W.H., and Podmore, F. Phantasms of the Living. London: Trubner, 1886.

Head, H. Aphasia and Kindred Disorders of Speech. Cambridge: University Press, 1926.

Ittelson, W. H., Kutash, S. B. Perceptual Changes in Psychopathology. New Brunswick, New Jersey: Rutgers University Press, 1961.

Jung, C. G. Psychological commentary. In W. Y. Evans-Wentz (Ed.), The Tibetan Book of the Dead. Third ed. London: Oxford University Press, 1957.

Klüver, H. Mechanisms of hallucinations. In Q. McNemar and M.A. Merrill (Eds.), Studies in Personality. New York: McGraw-Hill, 1942. 
Klüver, H. Mescal. London: Kegan Paul, 1928.

Klüver, H. Mescal vision and eidetic vision. American Journal of Psychiatry, 1926, 37, 502-515.

Lang, A. The other side of hallucinations: I. American Journal of Psychiatry, 1938, 94, 1089-1097.

Lang, A. The other side of hallucinations: II. American Journal of Psychiatry, 1939, 96, 423-430.

Leaf, H. What Is This Spiritualism? London: Cecil Palmer, 1918.

Leonard, G.O. My Life in Two Worlds. London: Cassell, 1931.

Licklider, J.C.R. Quasi-linear operator models in the study of manual tracking. In R.D. Luce (Ed.), Developments in Mathematical Psychology. Illinois: Free Press of Gencoe, 1960.

Moody, R.A. Life After Life. Atlanta: Mockingbird Books, 1975.

Myers, F.W.H. Human Personality and Its Survival of Bodily Death. London: Longmans Green, 1903.

Neppe, V.M. Symptomatology of temporal lobe epilepsy. South African Medical Journal, 1981, 60, 902-907.

Osgood, C.E. Method and Theory in Experimental Psychology. New York: Oxford University Press, 1953.

Osis, K., and Haraldsson, E. At the Hour of Death. New York: Avon Books, 1977.

Perls, F.S. Ego, Hunger and Aggression. London: George Allen and Unwin, 1947.

Prevost-Battersby, H.F. Psychic Certainties. London: Rider, n.d. but ca. 1930.

Ring, K. Life at Death. New York: Coward, McCann and Geoghegan, 1980.

Rogo, D.S. In Search of the Unknown. New York: Taplings, 1976.

Savage, C.W. The continuity of perceptual and cognitive experiences. In R.K. Siegel and L.J. West (Eds.), Hallucinations: Behavior, Experience, and Theory. New York: Wiley and Sons, 1975.

Schatzman, M. The Story of Ruth. London: Duckworth, 1980.

Shirley, R. The Mystery of the Human Double. New York: Olympia Press, 1972 (orig. pub. ca. 1930).

Siegel, R.K. The psychology of life after death. American Psychologist, $1980,35,911-931$.

Siegel, R.K., and West, L.F. (Eds.). Hallucinations: Behavior, Experience, and Theory. New York: Wiley and Sons, 1975.

Smythies, J.R. The experience and description of the body. Brain, 1953, 76, 132-145.

Troubridge, Lady (Una). The modus operandi in so-called mediumistic trance. Proceedings of the Society for Psychical Research, 1922, 32, 347-371. 
Troubridge, Lady (Una). Some further considerations of the modus operandi in mediumistic trance. Proceedings of the Society for Psychical Research, 1924, 34, 298-307.

Turvey, V.N. The Beginnings of Seership. London: Stead's Publishing House, n.d. but ca. 1911.

Tyrrell, G.N.M. Apparitions. London: Duckworth, 1953.

West, L.J. (Ed.). Hallucinations. New York: Grune and Stratton, 1962.

Whiteman, J.H.M. The Mystical Life. London: Faber and Faber, 1961.

\section{ADDENDUM}

Supplementary Note on the Definition of Pseudo-Hallucination

Since submitting the preceding paper, I have though it most necessary to answer in some detail a question addressed to me by a scholarly referee who reviewed the preliminary draft of this paper. The referee remarked that I should deal more explicitly with the distinction between hallucinations proper and pseudo-hallucinations as formulated by V. Kandinsky (1885) and perhaps also refer to the handling of the problem by Karl Jaspers (1913/1959).

Kandinsky defines pseudo-hallucinations as "extremely vivid and perfectly definite images which, however, differ from the truly hallucinatory images by not having the objective character of the latter. The conscious mind is clearly aware of them as subjective but at the same time as of something new and anomalous, utterly different from memory images and fancies." It should be noticed that my proposed definition of pseudo-hallucination in the body of the paper retains the actual phraseology, almost word for word, of Kandinsky.

Critics may point out that Kandinsky says nothing about pseudohallucinations having an "as if objective" character. I think otherwise. A patient of Kandinsky claimed that he soundlessly "heard" another person's thoughts. In such cases, Kandinsky granted that even though the pseudo-hallucinations are not mistaken for percepts, they are yet regarded in a certain sense, as "coming from without." In Kandinsky's schizophrenic cases, the external source was traced to one's enemies or even to God. Kandinsky suffered from periodic attacks of mania himself. He tried the effects of opium and experienced both hallucinations proper and pseudo-hallucinations before making the pioneering distinction. It is as least curious that some of his patients described pseudo-hallucinations as having a "clairvoyant," "clairaudient," or "spiritual" character, though I am not about to 
lodge a paranormal claim for them at this date. But it is clear that there was, in some cases at least, an overwhelming experience of translucency, of "looking through" opaque surroundings.

Jaspers refers to the remarkable hallucinations of Ludwig Staudenmaier, a professor of chemistry in a lyceum at Freising near Munich, who distinguished "subjective" from "objective" hallucinations. In the former, he posited an irradiating influence spreading from the visual center in the brain to the optic nerve and retinal structures. In "objective hallucinations," on the other hand, the irradiating influence spread in the reverse direction from the peripheral organ to the brain. Staudenmaier "heard" inner "communications" before writing them down. I note that Kandinsky reported cases of subjects "hearing" their own thoughts. Staudenmaier seemed also to have had the remarkable power of evoking quasi-visual and solid "phantoms" of people he knew or had met, quite in the manner of Morton Schatzman's subject, Ruth (Schatzman, 1980). Schatzman's work is therefore not as novel as some of his reviewers have believed, except for the instrumental check he introduced.

F. Kraupl Taylor (1918) contends that in the history of psychopathology, the term "pseudo-hallucination" has received two incompatible definitions: (a) a self-recognized exteroceptive or interoceptive hallucination; and (b) an introspected image of great spontaneity and vividness. I claim that my definition is a judicious compromise between these two apparently contradictory definitions. I claim further that my omnibus definition receives technical support from the work of the Italian researchers F. Felici and G.B. Laurenzi (1967) and L. Cancrini (1968), who describe "projected" visual hallucinations. I contend that my "as if objective" category is supported by clinical and experimental data. I can only hope that my referee, and others, will be moderately satisfied with this reply to his query about my methodology.

C.T.K. Chari

\section{REFERENCES}

Cancrini, L. Depressione neurotica e pseudoallucinazioni. Rivista di Psichiatria, 1968, 3, 12-26.

Felici, F., and Laurenzi, G.B. Allucinazioni extracampali: contributo clinico. Rivista di Psichiatria, 1967, 2, 470-475. 
Jaspers, K. Allgemeine Psychopathologie. Berlin: Springer-Verlag, 1913 (Seventh edition, 1959). Translated as General Psychopatho$\operatorname{logy}$ (J. Hoenig and M.W. Hamilton, trans.). Chicago: University of Chicago Press, 1963.

Kandinsky, V. Kritische und Klinische Betrachtungen im Gebiete der Sinnestäuschungen. Berlin: Friedländer, 1885; quoted in Lossky, N.O. Transsubjectivity of sense-qualities. Bulletin de l'Association Russe pour les Recherches Scientifiques a Prague, 1936, 4(21) (Section des Sciences, Philosophiques, Historiques, et Sociales), 26-28 and 115-129.

Schatzman, M. The Story of Ruth. New York: Putnam's, 1980.

Taylor, E.K. On pseudo-hallucinations. Psychological Medicine, $1981,11,265-271$.

Requests for reprints to:

Dr. C.T.K. Chari

The Cloister

No. 15 Vyasar Street

Tambaram East, Madras-59

Tamilnadu, India 